
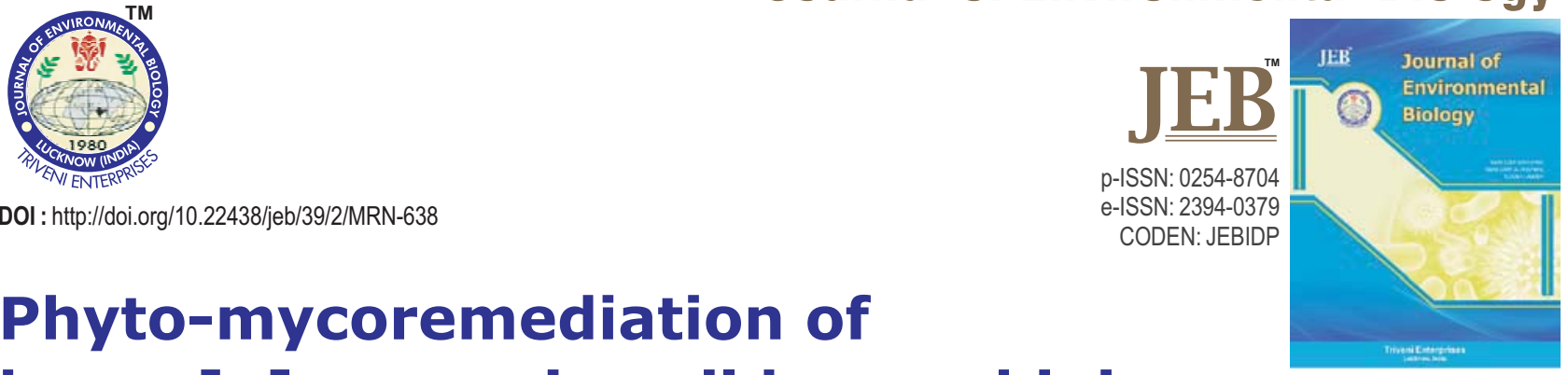

\title{
Phyto-mycoremediation of benzo[a]pyrene in soil by combining the role of yeast consortium and sunflower plant
}

Authors Info

\section{S.K. Mandal and N. Das* \\ Bioremediation Laboratory, School of Bio Sciences and Technology (SBST), VIT University, Vellore-632 014, India}

*Corresponding Author Email : nilanjana00@lycos.com

Key words

Benzo[a]pyrene Immobilization Phyto-mycoremediation Sunflower plant Yeast consortium

\section{Publication Info}

Paper received : 02.05.2017

Revised received : 12.07.2017

Re-revised received: 06.09.2017 Accepted: 13.10 .2017

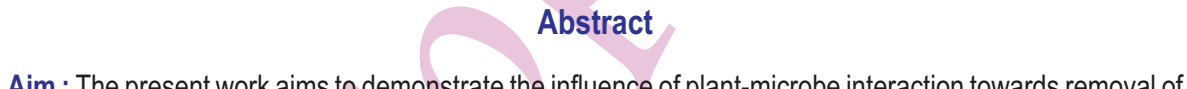

Aim : The present work aims to demonstrate the influence of plant-microbe interaction towards removal of benzo[a]pyrene $(\mathrm{BaP})$ in a microcosm through a phyto-mycoremediation approach using sunflower plant (Helianthus annuus) and yeast consortium.

Methodology : Sunflower plants were planted in pots containing BaP spiked soil. The rhizosphere of sunflower plant was amended with yeast consortium, YC01 consisting of Rhodotorula sp. NS01, Hanseniaspora opuntiae NS02 and Debaryomyces hansenii NSO3 by root inoculation. The soil containing $\mathrm{BaP}(50 \mathrm{mg}$ $\mathrm{kg}^{-1}$ ) were exposed to various treatments, monitored for a period of $45 \mathrm{~d}$ and residual $\mathrm{BaP}$ concentration was checked by GC-MS analysis.

Results: The removal of BaP was noted in the order of treatments as follows: rice husk immobilised phyto/myco remediation (93\%) $>$ phyto/ mycoremediation (82\%) > phytoremediation $(76 \%)>$ mycoremediation $(69 \%)$. The BaP removal rates from soil for the above treatments were expressed in terms of half-life period recorded as $11.31 \mathrm{~d}$, $17.07 \mathrm{~d}, 21.66 \mathrm{~d}$ and $25.38 \mathrm{~d}$, respectively. Dehydrogenase activity was increased greatly with time for the immobilised phytomycoremediation.

Interpretation : Bio-stimulation of soil with yeast consortium immobilized on rice husk enhanced the total activity of yeasts in the soil. Combined treatment using yeast consortium immobilized on rice husk and sunflower plant showed faster and

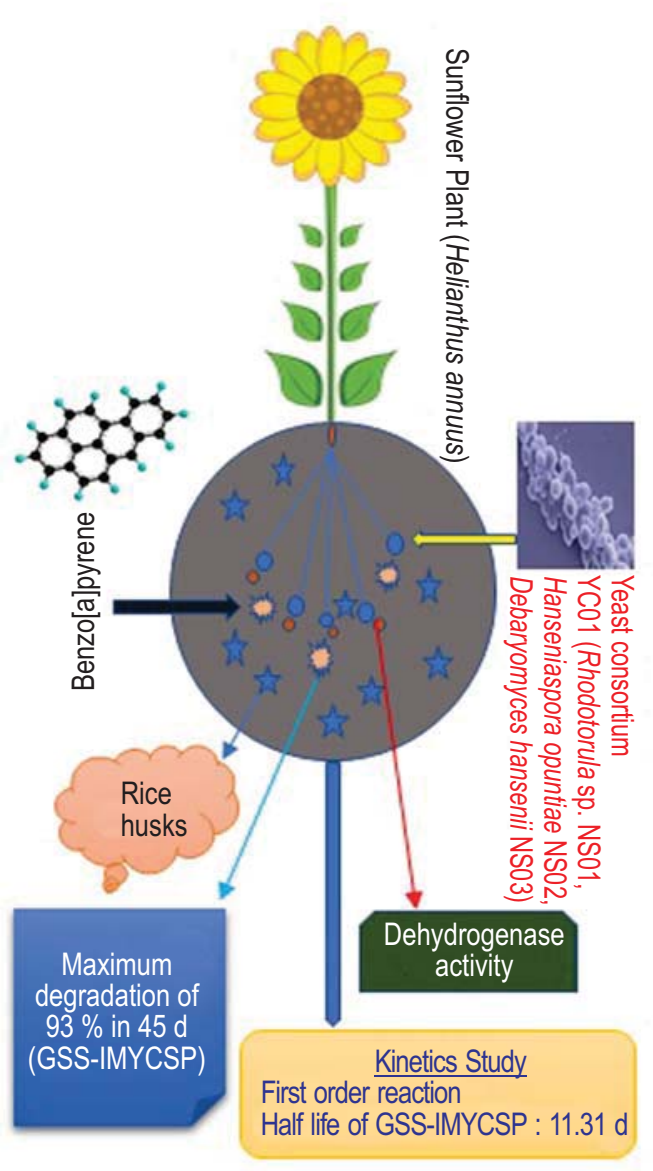
maximum $\mathrm{BaP}$ degradation. Therefore, it can be concluded that the use of sunflower plant along with yeast consortium as a dual approach can serve as an effective tool for remediation of $\mathrm{BaP}$ contaminated soil. 


\section{Introduction}

Polycyclic aromatic hydrocarbons (PAH) with high molecular weight having more than three benzene rings are difficult to degrade (Arulazhagan et al., 2014). Benzo[a]pyrene (BaP) containing five fused benzene rings is considered as priority pollutant by US-EPA representing HMW PAH and produced from incomplete combustion of organic matters (Mohandass et al., 2012; Bhattacharya et al., 2017). The potent sources of BaP include cigarette smoke, engine exhaust, fossil fuels, burning organic matter, petroleum spillage, industrial and urban runoff (Yim et al., 2017). Like other PAHs, BaP has become a matter of concern due to its toxicity, persistent and bioaccumulative nature, long-range transportable properties, high carcinogenicity, high chemical stability, mutagenesis and teratogenic characteristics (Balaji et al., 2014; Alrumman etal., 2016; Guo etal., 2017).

Phytoremediation is an emerging, sustainable and convenient remediation technique which involves low treatment costs for stabilization and environmental improvement to clean up contaminated soil (Chayapan et al., 2015; Willscher et al., 2017). Applicability of phytoremediation for decontaminating PAHscontaminated soils has been reported using plants such as sunflower (Helianthus annuus L.) (Tejeda-Agredano et al., 2013), rice (Oryza sativa) (Ma et al., 2015), Zea mays L. cv PR32-B10 (Barone et al., 2016) and Medicago sativa (Alves et al., 2017). The plants referred in the above papers showed good performance in terms of $\mathrm{PAH}$ remediation, however, reports on phytoremediation of BaP is meagre (Gutiérrez-Ginés et al., 2014; Li etal., 2016).

Sunflower plant has been reported as the best plant species among eleven dicotyledonous plants for assaying the PAH bioavailability (Olson et al., 2007). There is report that rhizosphere of sunflower plant removes a greater quantity of PAHs such as anthracene, fluorene and pyrene from contaminated soil (Maliszewska-Kordybach and Smreczak, 2000). Moreover, sunflower root exudates were chemically characterized and tested for the effectiveness on biodegradation by soil microorganisms (Tejeda-Agredano et al., 2013). Though sunflower has been focused as a model plant for use in PAH rhizoremediation, however use of this plant for remediation of benzo[a]pyrene $(\mathrm{BaP})$ from soil in meagre. There are certain limitations while using plants as phytoremediators such as they lack the catabolic pathways for complete degradation or mineralization of externally added organic compounds. Rhizoremediation has gained attention for the removal of organic pollutants like PAHs. Microbial utilization of root exudates and translocation of dissolved contaminants in the rhizosphere have been proposed as mechanisms of PAHs elimination using plants (Newman and Reynolds, 2004). PAH degrading soil microorganisms have access to rhizodeposits derived from plant roots and plants help the microbes for this function.

The yeast consortium YC01 consisting of Rhodotorula sp. NS01, Hanseniaspora opuntiae NS02 and Debaryomyces hansenii NS03 proved as potent BaP degrader which showed the capacity to degrade $76.0 \% \mathrm{BaP}$ in aqueous medium with a halflife of $3.03 \mathrm{~d}$ (Mandal et al., 2016). In this context, the main objective of the present study was to evaluate the influence of plant-microbe interaction towards $\mathrm{BaP}$ removal from soil through a phyto-mycoremediation approach using sunflower plant and yeast consortium YC01.

\section{Materials and Methods}

Soil collection and sampling : The soil was collected from the nursery in VIT University, Vellore which had no record of BaP contamination previously. The $\mathrm{pH}$ of soil sample was 7.9 and classified as loamy clay containing $2.4 \%$ organic carbon, $6 \%$ sand, $25 \%$ silt and $56 \%$ clay. The collected soil was air dried, sieved and amended with biomanure. BaP dissolved in chloroform to a final concentration of $50 \mathrm{mg} \mathrm{kg}^{-1}$ was added to soil and mixed well. After the solvent was evaporated in laminar hood, the garden spiked soils (GSS) were used for pot experiments.

Plants and microorganisms used : The yeast consortium, YC01 (Mandal et al., 2016) and seeds of sunflower (Helianthus annuus) were used. $\mathrm{BaP}$ at a concentration of $50 \mathrm{mg} \mathrm{kg}^{-1}$ was dissolved in chloroform and the dissolved solution was spiked into the soil.

For immobilization of yeast consortium, rice husk was collected and dried at $60^{\circ} \mathrm{C}$ for $24 \mathrm{hrs}$. The sterile rice husks were added into YEPD broth cultures containing yeast consortium, YC01 and incubated for $7 \mathrm{~d}$ at $30{ }^{\circ} \mathrm{C}$ for yeast growth and immobilization on rice husk. Thick biofilm was formed on the surface of the husk after incubation.

Experimental design : Soil experiments were performed in black colour plastic pot (140 mm diameter; $140 \mathrm{~mm}$ height). The BaP spiked soil was filled in five batches of pots. Experiments were conducted in triplicates for each treatment. The treatments were as follows : Abiotic control (GSS-AC) : Garden spiked soil; Mycoremediation treatment (GSS-YC) : Garden spiked soil inoculated with yeast consortium, YC01; Phytoremediation treatment (GSS-SP): Garden spiked soil treated with sunflower plant (Helianthus annuus); Phyto-myco remediation treatment (GSS-YCSP) : Garden spiked soil treated with the yeast consortium in combination with sunflower plant (Helianthus annuus); Phyto-myco remediation with biostimulation by rice husks (GSS-IMYCSP) : Garden spiked soil treated with immobilized yeast consortium in combination with sunflower plant (Helianthus annuus) and Plant control (GNSS-plant) : Garden non-spiked soil treated sunflower plant (Helianthus annuus).

The GSS and GNSS were amended with respective treatments and transferred into the pots to ensure homogeneity. All the treatments were maintained for $45 \mathrm{~d}$ under ex-situ conditions. All pots were watered to maintain soil close to field capacity. Soil samples were collected every $10 \mathrm{~d}$ and stored at 4 
${ }^{\circ} \mathrm{C}$ before chemical and biological analysis. The soil samples were serially diluted and spread on nutrient agar for bacteria and streptomycin-YEPD agar for yeast to enumerate the viable microbial population. The plates were incubated for $4 \mathrm{~d}$ at $30^{\circ} \mathrm{C}$ and the number of colony forming units (CFU) were counted.

Analysis of residual BaP : Two gram of refrigerated soil sample was extracted three times by ultrasonic treatment for 20 min with an Ultrasonic Disrupter containing $30 \mathrm{ml}$ mixture of hexaneacetone (1:1) followed by centrifugation at $3000 \mathrm{rpm}$ for $10 \mathrm{~min}$ to separate the supernatant from the soil. The supernatant was collected in a $100 \mathrm{ml}$ round bottom flask (Sun et al., 1998). The extract was concentrated using rotary evaporator and redissolved in hexane before analysis. Residual BaP was quantified by gas chromatography (Zhao et al., 2014). Residual BaP concentration after degradation was calculated comparing the peak area of the sample and control.

Kinetic study : The experimental data on the degradation kinetics of $\mathrm{BaP}$ were fitted using the simple first order kinetics equation (Kot-Wasik et al., 2004).

Plant growth measurement : The heights of sunflower plants were measured after definite interval of time for all the treatments. After $45 \mathrm{~d}$ of growth, the plants were harvested and washed in tap water followed by distilled water, dried and weighed.

Dehydrogenase activity : Soil dehydrogenase activity was measured following the standard method (Cheema et al., 2010) by the reduction of triphenyl tetrazolium chloride (TTC) to triphenyl formazan (TPF). Five gram soil sample was incubated for $24 \mathrm{hrs}$ at $37^{\circ} \mathrm{C}$ in $5 \mathrm{ml}$ of TTC solution $\left(5 \mathrm{~g} \mathrm{l}^{-1}\right.$ in $0.2 \mathrm{moll}^{-1}$ Tris- $\mathrm{HCl}$ buffer, $\mathrm{pH}$ 7.4). Two drops of concentrated $\mathrm{H}_{2} \mathrm{SO}_{4}$ were immediately added after incubation to stop the reaction. The sample was then blended with $5 \mathrm{ml}$ of toluene to extract TPF and shaken for $30 \mathrm{~min}$ at $250 \mathrm{rpm}\left(25^{\circ} \mathrm{C}\right)$, followed by centrifugation at $5000 \times \mathrm{g}$ for $5 \mathrm{~min}$. The absorbance of color in the extract was taken at $492 \mathrm{~nm}$. Soil dehydrogenase activity was measured in terms of $\mu \mathrm{g}$ TPF g ${ }^{-1}$ dry soil $24 \mathrm{hr}^{-1}$.
Indole acetic acid (IAA) production : Experiment was conducted to quantify the production of IAA (Gordon and Weber, 1951). Yeast consortium, YC01 was grown in YEPD medium without or with 0.1 $\%\left(w^{-1}\right)^{-}$L-tryptophan for $1,2,5$, and $7 \mathrm{~d}$. $1.5 \mathrm{ml}$ of yeast cells were pelleted by centrifugation at $10000 \times \mathrm{g}$ for $5 \mathrm{~min}$. One $\mathrm{ml}$ of supernatant was mixed with $2 \mathrm{ml}$ of Salkowski's reagent $(2 \mathrm{ml} 0.5 \mathrm{M}$

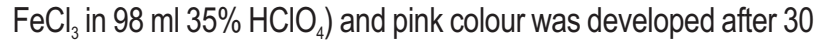
min. The intensity of pink color was measured using a colorimeter (Elico-CL157) at wavelength $530 \mathrm{~nm}$.

Characterization of degraded products by FTIR analysis : FTIR spectra of pure BaP and degraded products were used to determine the vibrational frequency changes in their functional groups. The extracted degraded products dissolved in ethyl acetate were mixed with $\mathrm{KBr}$ and made in the forms of pellets. Infrared spectroscopy was investigated with an IR affinity-1 FTIR spectrophotometer (Shimadzu). The scanning wavelength range was kept from 4,000 to $400 \mathrm{~cm}^{-1}$ and the spectral resolution was $4 \mathrm{~cm}^{-1}$.

Statistical analysis : Mean of three replications was considered as the final reading for all the analysis. Data were analysed using analysis of variance (ANOVA) using Prism6 software (Graph Pad Inc.) to determine the significance of difference between the treatments on $\mathrm{BaP}$ degradation in the pot experiments. The statistical significance in this analysis was defined at $p<0.05$.

\section{Results and Discussion}

The combined treatment of BaP degrading yeast consortium and sunflower plant improved the microbial activity in the soil. It was found that bacterial and yeast counts in the sunflower planted soil were remarkably higher compared with the soil without plant. In addition, the bio-stimulation of soil with yeast species increased the bacterial activity in the soil (Table 1). The non-indigenous yeasts and indigenous bacteria might have established a positive interaction in the soil. The yeast consortium immobilized on rice husk showed greater efficiency on improvement of microbial activity in the soil compared to the

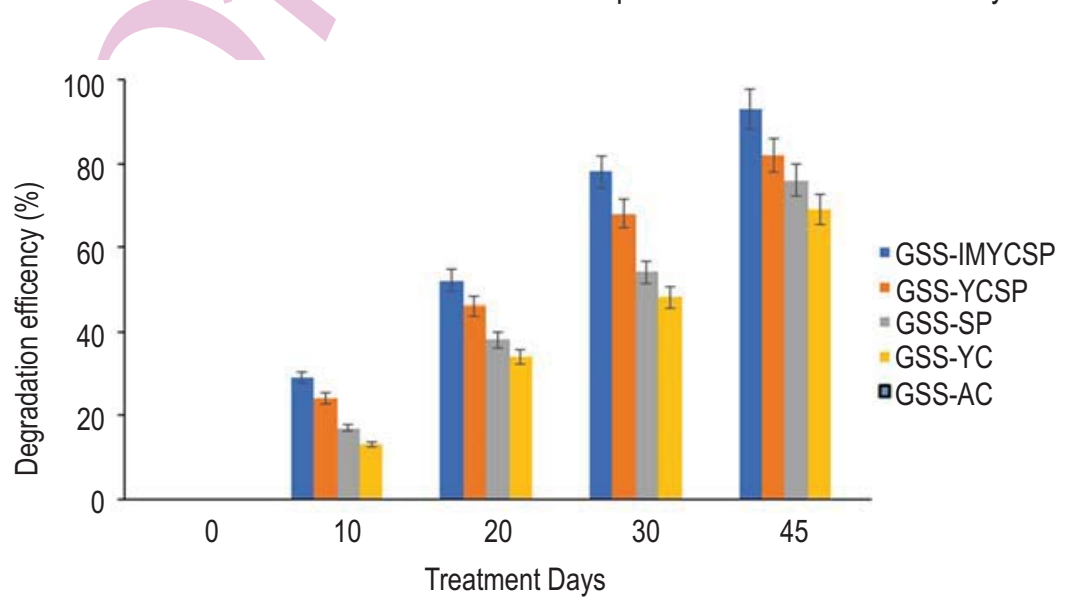

Fig. 1 : Effects of various treatments on benzo[a]pyrene degradation in the pot-microcosm experiment 
yeast in free form. After $45 \mathrm{~d}$ of experiment, GSS + Immobilized yeast consortium + Sunflower plant showed the maximum bacterial count of $6.6 \times 10^{9} \mathrm{CFU} \mathrm{g}{ }^{-1}$ dry soil and yeast count of $8.7 \times 10^{5} \mathrm{CFU} \mathrm{g}^{-1}$ dry soil which were $1-1.2$ times higher than other treatments. Tejeda-Agredano et al. (2013) reported that there was an increase in number of the population of high-molecularweight (HMW) PAH degraders in the sunflower planted soils compared to the unplanted controls which demonstrated the selective influence of the sunflower rhizosphere on these microbial populations. The rhizosphere is reported to have a complex ecology with numerous feedback loops that regulate microbial populations (Toal et al., 2000). Moreover, root exudation, water and nutrient fluxes create quantitative and qualitative spatial gradients which affect microbial populations (Fang et al., 2001; Butler et al., 2003). This is in agreement with our results where sunflower plant may have increased the number of $\mathrm{BaP}$ degrading microbial population in garden spiked soil.
The sunflower plant started sprouting from $3^{\text {rd }} \mathrm{d}$ itself in all the treatments. It was seen that the yeast consortium immobilized on rice husk had a profound effect on plant growth and maximum plant growth was noted in the GSS-IMYCSP treatment, whereas GSS-SP treatment showed minimum plant growth (Table 2). The bio-stimulation of garden soil with rice husk enhanced the nutritional value of soil for better growth of the plant. The experimental results implied that rhizoinoculation of sunflower with yeast consortium had mutual benefit for microbial as well as plant growth.

Plant biomass was measured at the end of experiment to explore the ability of plant species to grow in BaP spiked garden soil. No significant reduction in plant height and biomass was noted in GSS-SP treatment after $45 \mathrm{~d}$.

Fig. 1 shows the removal of $\mathrm{BaP}$ after $45 \mathrm{~d}$ confirming that all the remediation treatments were involved in $\mathrm{BaP}$ removal from

Table 1 : Microbial plate counts in garden soil spiked with benzo[a]pyrene at regular intervals for various treatments $(p<0.05)$

\begin{tabular}{|c|c|c|c|c|c|c|c|c|c|c|}
\hline \multirow[t]{3}{*}{ Treatment } & \multicolumn{5}{|c|}{ Total bacterial count (CFU ml ${ }^{-1}$ ) } & \multicolumn{5}{|c|}{ Total yeast count (CFU ml' ${ }^{-1}$ ) } \\
\hline & \multicolumn{10}{|c|}{ No. of days } \\
\hline & $0^{\text {th }}$ & $10^{\text {th }}$ & $20^{\text {th }}$ & $30^{\text {th }}$ & $45^{\text {th }}$ & $0^{\text {th }}$ & $10^{\text {th }}$ & $20^{\text {th }}$ & $30^{\text {th }}$ & $45^{\text {th }}$ \\
\hline GSS-AC & $2.5 \times 10^{9}$ & $2.3 \times 10^{9}$ & $2.7 \times 10^{9}$ & $3.1 \times 10^{9}$ & $3.5 \times 10^{9}$ & - & - & - & - & - \\
\hline GSS-YC & $2.5 \times 10^{9}$ & $3.6 \times 10^{9}$ & $4.9 \times 10^{9}$ & $5.2 \times 10^{9}$ & $5.4 \times 10^{9}$ & $1.4 \times 10^{4}$ & $3.8 \times 10^{4}$ & $4.4 \times 10^{5}$ & $6.4 \times 10^{5}$ & $7.1 \times 10^{5}$ \\
\hline GSS-SP & $2.5 \times 10^{9}$ & $3.9 \times 10^{9}$ & $5.4 \times 10^{9}$ & $6.7 \times 10^{9}$ & $7.6 \times 10^{9}$ & - & - & - & - & - \\
\hline GSS-YCSP & $2.5 \times 10^{9}$ & $3.7 \times 10^{9}$ & $5.1 \times 10^{9}$ & $6.3 \times 10^{9}$ & $6.8 \times 10^{9}$ & $1.4 \times 10^{4}$ & $4.7 \times 10^{4}$ & $5.2 \times 10^{5}$ & $7.6 \times 10^{5}$ & $8.3 \times 10^{5}$ \\
\hline GSS-IMYCSP & $2.5 \times 10^{9}$ & $3.9 \times 10^{9}$ & $5.0 \times 10^{9}$ & $6.1 \times 10^{9}$ & $6.6 \times 10^{9}$ & $1.4 \times 10^{4}$ & $5.3 \times 10^{4}$ & $6.2 \times 10^{5}$ & $7.9 \times 10^{5}$ & $8.7 \times 10^{5}$ \\
\hline
\end{tabular}

Table 2: Changes in shoot length of sunflower plants after various treatments

\begin{tabular}{lllllll}
\hline Days & \multicolumn{5}{c}{ Shoot height } \\
\cline { 2 - 6 } & $\begin{array}{l}\text { GSS-AC } \\
\text { Abiotic control }\end{array}$ & $\begin{array}{l}\text { GSS-YC } \\
\text { Mycoremediation }\end{array}$ & $\begin{array}{l}\text { GSS-SP } \\
\text { Phytoremediation }\end{array}$ & $\begin{array}{l}\text { GSS-YCSP } \\
\text { Phyto-mycoremediation }\end{array}$ & $\begin{array}{l}\text { GSS-IMYCSP } \\
\text { Phyto-mycoremediation } \\
\text { cum biostimulation }\end{array}$ & $\begin{array}{l}\text { GNSS-Plant } \\
\text { Plant control }\end{array}$ \\
\hline 0 & - & - & & & - & - \\
10 & - & - & $4.8 \pm 0.03 \mathrm{~cm}$ & $7.3 \pm 0.08 \mathrm{~cm}$ & $10.4 \pm 0.05 \mathrm{~cm}$ & $5.0 \pm 0.06 \mathrm{~cm}$ \\
20 & - & - & $10.9 \pm 0.07 \mathrm{~cm}$ & $13.4 \pm 0.06 \mathrm{~cm}$ & $19.6 \pm 0.02 \mathrm{~cm}$ & $11.1 \pm 0.07 \mathrm{~cm}$ \\
30 & - & - & $19.7 \pm 0.06 \mathrm{~cm}$ & $24.3 \pm 0.01 \mathrm{~cm}$ & $27.2 \pm 0.03 \mathrm{~cm}$ & $20.2 \pm 0.09 \mathrm{~cm}$ \\
45 & - & - & $26.7 \pm 0.04 \mathrm{~cm}$ & $30.7 \pm 0.10 \mathrm{~cm}$ & $38.5 \pm 0.07 \mathrm{~cm}$ & $27.1 \pm 0.03 \mathrm{~cm}$ \\
\hline
\end{tabular}

Table 3 : The first-order kinetic parameters of benzo[a]pyrene degradation

\begin{tabular}{lllll}
\hline Treatments & Kinetic equation & $\mathbf{K}\left(\mathbf{d}^{-1}\right)$ & $\mathbf{T}_{1 / 2}(\mathbf{d})$ & $\mathbf{R}^{2}$ \\
\hline GSS-YC & $\ln \mathrm{Ct}=-0.027 \mathrm{t}+3.996$ & 0.027 & 25.385 & 0.979 \\
GSS-SP & $\ln \mathrm{Ct}=-0.032 \mathrm{t}+4.007$ & 0.032 & 21.656 & 0.981 \\
GSS-YCSP & $\ln \mathrm{Ct}=-0.041 \mathrm{t}+4.022$ & 0.041 & 17.069 & 0.983 \\
GSS-IMYCSP & $\ln \mathrm{Ct}=-0.061 \mathrm{t}+4.093$ & 0.061 & 11.305 & 0.987 \\
\hline
\end{tabular}




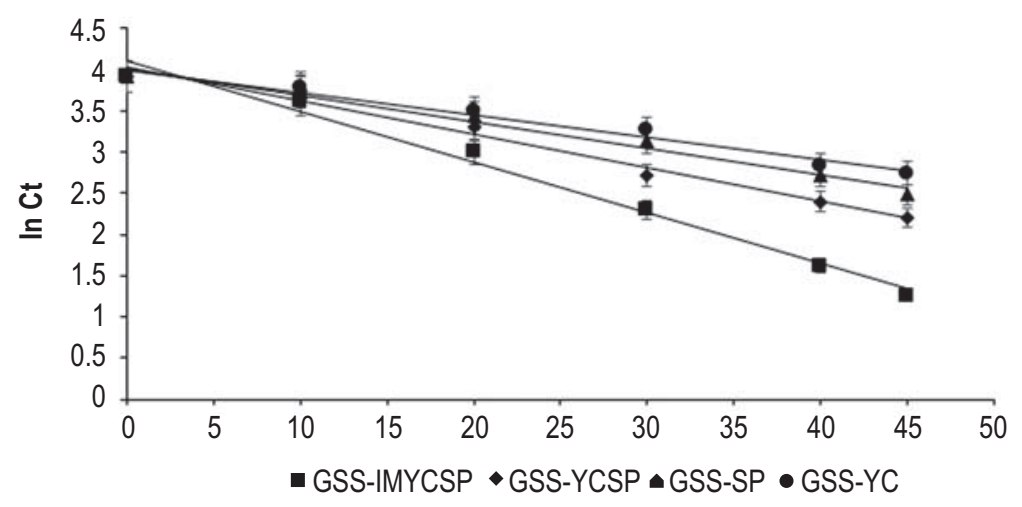

Fig. 2 : Kinetic plot of first-order model for benzo[a]pyrene degradation by various treatments in soil experiment

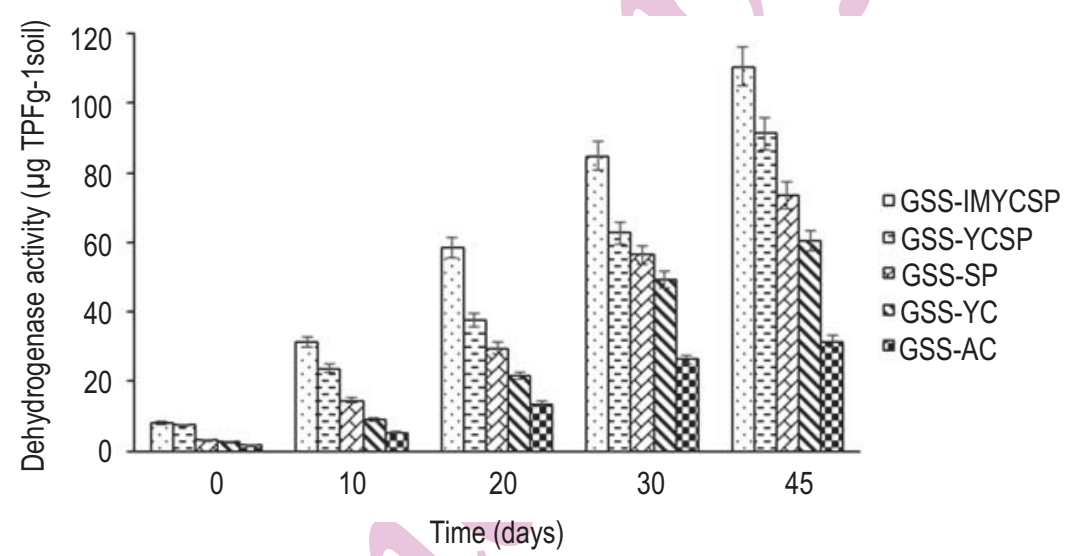

Fig. 3 : Activity of dehydrogenase enzyme noted in soil microcosm study

soil. However, the removal of $\mathrm{BaP}$ in the abiotic control was relatively negligible over the study period, as removal was less than $1 \%$ in the abiotic control (GSS-AC). Individually, the treatment GSS-SP resulted $76 \%$ of BaP removal whereas the GSS-YC contributed only to $69 \%$ of $\mathrm{BaP}$ degradation. Therefore, based on the results, it can be inferred that BaP removal was enhanced in dual phyto-myco treatments (GSS-YCSP and GSSIMYCSP) than individual treatments (GSS-YC and GSS-SP). This was the result of synergistic effect on plant-microbe interaction. The removal of BaP was found to be $82 \%$ in the treatment GSS-YCSP, where yeast consortium was added in free cell form. The removal percentage of $\mathrm{BaP}$ was further enhanced by bio-stimulating the treatment with rice husk in the GSSIMYCSP treatment. The results showed that immobilization of yeast consortium in rice husk had a profound effect on BaP degradation probably due to the fact that rice husk contains abundant cellulose rich in nutrient and exhibit excellent biocompatibility. Rice husk is considered suitable for immobilization of biological compounds (Pode, 2015; He et al., 2016) which could promote the activity of yeast strains due to stimulating effect. The results of the residual $\mathrm{BaP}$ analysis confirmed that GSS-IMYCSP treatment showed maximum efficiency resulting $93 \%$ removal of BaP from the garden spiked soil at the end of $45 \mathrm{~d}$ compared to all other treatments. Attachment, adsorption and enhanced secretion through rice husk could be a reason for enhanced activity in GSS-IMYCSP treatment of the present study.

It was clearly understood that the association of $\mathrm{BaP}$ degrading indigenous bacteria along with yeast consortium and sunflower plant showed profound effect on $\mathrm{BaP}$ dissipation which ultimately resulted in reduction of half-life period $\left(\mathrm{T}_{1 / 2}\right)$ to $11.31 \mathrm{~d}$. The kinetic rate constant was also found to be maximum in the GSS-IMYCSP treatment being 0.0613 perd (Fig. 2 and Table 3 ).

Therefore, the results of the present study on ex-situ removal of BaP from garden spiked soil showed that there is also a scope for other native plants and various microorganisms in combination for field trial towards efficient removal of BaP. The sunflower plant-yeast consortium inoculation can be useful as a cheap and effective alternative for biotreatment of BaP contaminated soil.

Assay on dehydrogenase activity in soil is carried out to obtain correlative information on the biological activity of microbial populations in soil, i.e., as an index of total microbial activity (Cheema et al., 2009; Cheema et al., 2010). Fig. 3 shows that the dehydrogenase activities were much higher in planted 
soils compared to unplanted, controls irrespective to the presence of $\mathrm{BaP}$ in soil. Highest dehydrogenase activity was observed in the rhizosphere of immobilised rice husk + sunflower plant + yeast consortium (GSS-IMYCSP treatment), whereas lowest values were noted in the rhizosphere of yeast consortium alone (GSS-YC). This matches well with the BaP degradation data.

Many plant growth promoting microbes use a prominent mechanism to facilitate the plant growth through the production of phytohormones viz., indole acetic acid, cytokinins etc (Zaidi et al., 2015; Vejan et al., 2016). The yeast consortium, YC01 was identified to possess plant growth promoting property of IAA production and positive result was obtained which confirmed the ability of yeast consortium, YC01 in promoting plant growth. There are reports on seventeen yeast strains ( Ignatova et al., 2014) and seventy seven yeast strains (Ignatova et al., 2015) isolated from soil as plant growth promoting microorganisms producing IAA.

In Fig. 4, FTIR spectra of BaP (control) showed the characteristic absorption peaks at $3028.24 \mathrm{~cm}^{-1}$ corresponding to $=\mathrm{C}-\mathrm{H}$ stretch in aromatic hydrocarbon. The absorption peaks at $1467.83 \mathrm{~cm}^{-1}$ and $1176.58-1346.31 \mathrm{~cm}^{-1}$ represents C-C stretch in

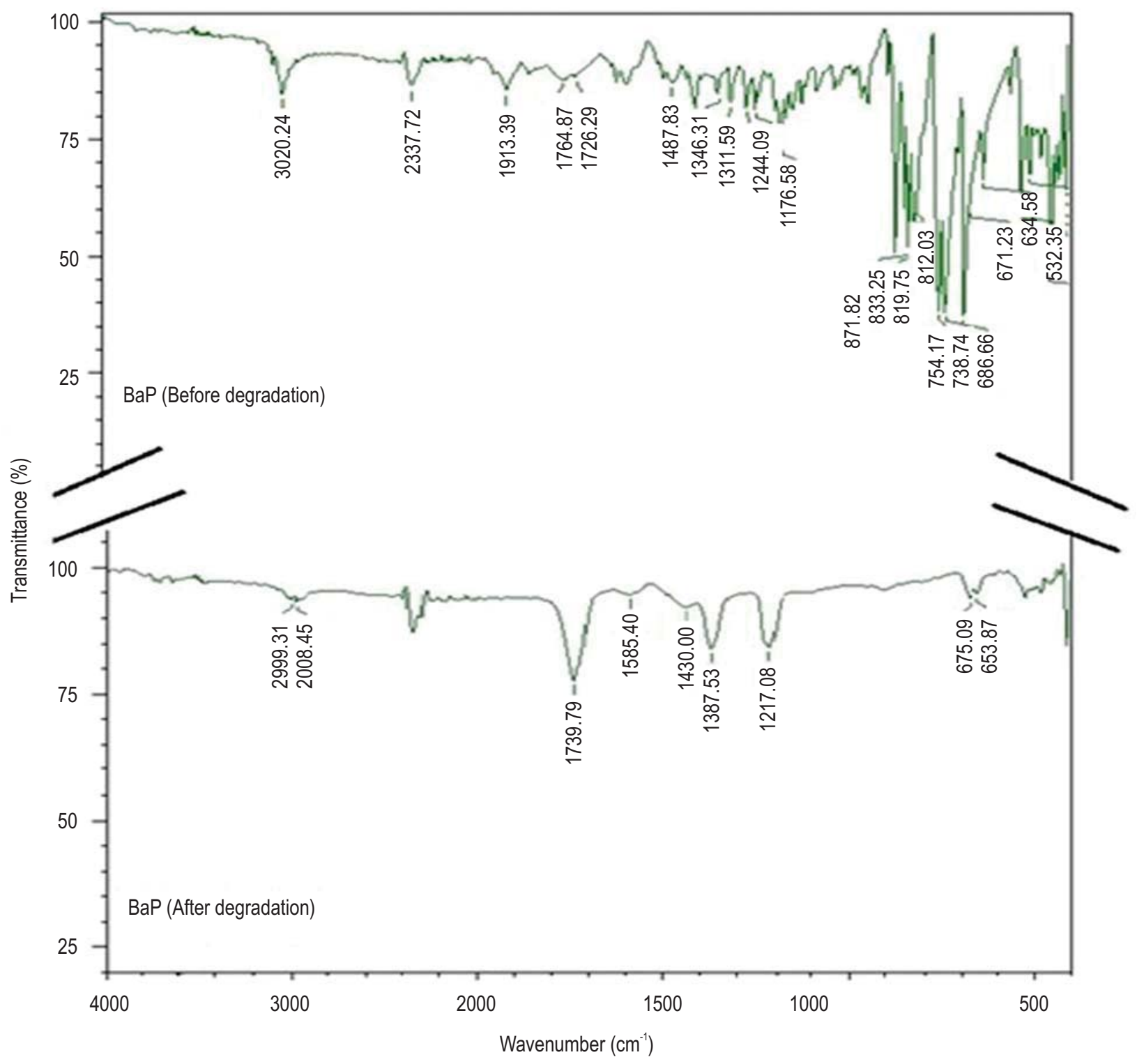

Fig. 4 : FTIR analysis of benzo[a]pyrene (before and after degradation) in the GSS-IMYCSP treatment after 45 days 
aromatic benzene rings. Strong peaks at between 871.82-671.23 $\mathrm{cm}^{-1}$ corresponds to $=\mathrm{C}-\mathrm{H}$ bend. The appearance of new peaks viz. $2999.31 \mathrm{~cm}^{-1}$ corresponds to $=\mathrm{C}-\mathrm{H}$ stretch in $-\mathrm{OH}$ group in aromatic unsaturated hydrocarbons, $2968.45 \mathrm{~cm}^{-1}$ ( $\mathrm{CH}$ antisym and sym stretching in methyl or ethyl groups), $1739.79 \mathrm{~cm}^{-1}$ (strong $\mathrm{C}=0$ stretch in aldehydes groups), $1586.49 \mathrm{~cm}^{-1}$ (very strong $\mathrm{C}=\mathrm{O}$ stretch in enol form of diketones groups), $1438.90 \mathrm{~cm}^{-1}$ (medium strong in plane $\mathrm{OH}$ bending in carboxylic acids groups), $1367.53 \mathrm{~cm}^{-1}$ (medium strong $\mathrm{CH} 3$ deformation in isopropyl group), $1217.08 \mathrm{~cm}^{-1}$ (strong C-O-C antisym stretch in vinyl esters groups) (Mandal et al., 2016) and 675.09-663.87 $\mathrm{cm}^{-1}$ (strong C$\mathrm{O}-\mathrm{H}$ bending in alcohols groups) were noted in the IR spectra of degraded $\mathrm{BaP}$ on $45 \mathrm{~d}$ in the treatment GSS- IMYCSP.

Based on the results of the present study, it can be concluded that laboratory scale experiments can be conducted for successful bioremediation of benzo[a]pyrene (BaP) through phyto-mycoremediation approach using sunflower plant and yeast consortium.

\section{Acknowledgments}

We thank SAS, VIT University, Vellore for helping us in GC-MS and FTIR analysis. Financial assistance and laboratory facilities provided by VIT University, Vellore, Tamil Nadu, India is acknowledged.

\section{References}

Alrumman, S.A., A.E.L. Hesham and S.A. Alamri: Isolation, fingerprinting and genetic identification of indigenous PAHs degrading bacteria from oil-polluted soils. J. Environ. Bio., 37, 75-81 (2016).

Alves, W.S., E.A. Manoel, N.S. Santos, R.O. Nunes, G.C. Domiciano and M.R. Soares: Detection of polycyclic aromatic hydrocarbons (PAHs) in Medicago sativa L. by fluorescence microscopy. Micron, 95, 23-30 (2017).

Arulazhagan, P., C. Sivaraman, S.A. Kumar, M. Aslam and J.R. Banu: Co-metabolic degradation of benzo(e)pyrene by halophilic bacterial consortium at different saline conditions. J. Environ. Bio., 35, 445-452 (2014).

Balaji, V., P. Arulazhagan and P. Ebenezer: Enzymatic bioremediation of polyaromatic hydrocarbons by fungal consortia enriched from petroleum contaminated soil and oil seeds. J. Environ. Bio., 35, 521-529 (2014).

Barone, R., M.G.D. Biasi, V. Piccialli, L.D. Napoli, G. Oliviero, N. Borbone and G. Picciall: Degradation of some representative polycyclic aromatic hydrocarbons by the water-soluble protein extracts from Zea mays L. cv PR32-B10. Chemosphere, 160, 258-265(2016).

Bhattacharya, S., A. Das, M. Palaniswamy and J. Angayarkanni : Degradation of benzo[a]pyrene by Pleurotus ostreatus PO-3 in the presence of defined fungal and bacterial co-cultures. J. Basic Microbiol., 57, 95-103 (2017).

Butler, J.L., M.A. Williams, P.J. Bottomley and D.D. Myrold: Microbial community dynamics associated with rhizosphere carbon flow. Appl. Environ. Microbiol., 69, 6793-6800 (2003).

Chayapan, P., M. Kruatrachue, M. Meetam and P. Pokethitiyyok: Phytoremediation potential of $\mathrm{Cd}$ and $\mathrm{Zn}$ by wetland plants, Colocasia esculenta L. Schoot., Cyperus malaccensis Lam., and Typha angustifolia L. grown in hydroponics. J. Environ. Bio., 36,
1179-1183(2015)

Cheema, S.A., M.I. Khan, X. Tang, C. Zhang, C. Shen, Z. Malik, S. Ali, J. Yang, K. Shen, $X$. Chen and Y. Chen : Enhancement of phenanthrene and pyrene degradation in rhizosphere of tall fescue (Festuca arundinacea). J. Hazard. Mater., 166, 1226-1231 (2009).

Cheema, S.A., M.I. Khan, C. Shen, X. Tang, M. Farooq, L. Chen, C. Zhang, and $Y$. Chen: Degradation of phenanthrene and pyrene in spiked soils by single and combined plants cultivation. J. Hazard. Mater., 177, 384-389 (2010).

Fang, C., M. Radosevich and J.J. Fuhrmann: Characterization of rhizosphere microbial community structure in five similar grass species using FAME and BIOLOG analyses. Soil Biol. Biochem., 33, 679-682 (2001).

Gordon, S.A. and R.P. Weber: Colorimetric estimation of indole acetic acid. Plant Physiol., 26, 192 (1951).

Guo, R., L. Pan, P. Lin and L. Zheng: The detoxification responses, damage effects and bioaccumulation in the scallop Chlamys farreri exposed to single and mixtures of benzo[a]pyrene and chrysene. Comp. Biochem. Phys. C, 191, 36-51 (2017).

Gutiérrez-Ginés, M.J., A.J. Hernández, M.I. Pérez-Leblic, J. Pastor and J. Vangronsveld: Phyto-remediation of soils co-contaminated by organic compounds and heavy metals : Bioassays with Lupinus luteus $L$. and associated endophytic bacteria. J. Environ. Manage., 143, 197-207 (2014).

He, M., Y. Li, F. Pi, J. Ji, X. He, Y. Zhang and X. Sun: A novel detoxifying agent: Using rice husk carriers to immobilize zearalenonedegrading enzyme from Aspergillus niger FS10. Food Control, 68, 271-279 (2016). doi: 10.1016/j.foodcont.2016.03.042

Ignatova, L.V., T. D. Mukasheva, E. Brazhnikova and R.Z. Berzhanova: Isolation of IAA-producing yeasts from soil under Alfaalfa (Medicago sativa) in Kazakhstan. J. Biotechnol., 185, S64 (2014).

Ignatova, L.V., Y.V. Brazhnikova, R.Z. Berzhanova and T.D. Mukasheva: Plant growth-promoting and antifungal activity of yeasts from dark chestnut soil. Microbiol. Res., 175, 78-83 (2015).

Kot-Wasik, A., D. Dabrowska and J. Namiesnik: Photodegradation and biodegradation study of benzo(a)pyrene in different liquid media. J. Photoch. Photobio. Chem., 168, 109-115(2004).

Li, R.L., B.B. Liu, Y.X. Zhu and Y. Zhang: Effects of flooding and aging on phytoremediation of typical polycyclic aromatic hydrocarbons in mangrove sediments by Kandelia obovata seedlings. Ecotox. Environ. Safe., 128, 118-125(2016).

Ma, B., X.F. Lyu, T. Zha, J. Gong, Y. He and J.M. Xu: Reconstructed metagenomes reveal changes of microbial functional profiling during PAHs degradation along a rice (Oryza sativa) rhizosphere gradient. J. Appl. Microbiol., 118, 890-900 (2015).

Maliszewska-Kordybach, B. and B. Smreczak: Ecotoxicological activity of soils polluted with polycyclic aromatic hydrocarbons (PAHs)effect on plants. Environ. Technol., 21, 1099-1110 (2000).

Mandal, S.K., A. Selvi and N. Das: A novel approach on degradation of benzo[a]pyrene by yeast consortium isolated from contaminated soil. DerPharmacia Lett., 8, 80-93 (2016).

Mohandass, R., P. Rout, S. Jiwal and C. Sasikala: Biodegradation of benzo[a]pyrene by the mixed culture of Bacillus cereus and Bacillus vireti from the petrochemical industry. J. Environ. Biol., 33, 985-989 (2012).

Newman, L.A. and C.M. Reynolds : Phytodegradation of organic compounds. Curr. Opin. Biotech., 15, 225-230 (2004).

Olson, P.E., A. Castro, M. Joern, N.M. DuTeau, E.A.H. Pilon-Smits, and K.F. Reardon : Comparison of plant families in a greenhouse phytoremediation study on an aged polycyclic aromatic hydrocarbon-contaminated soil. J. Environ. Qual., 36, 14611469 (2007).

Pode, R.: Potential applications of rice husk ash waste from rice husk 
biomass power plant. Renew. Sust. Energ. Rev., 53, 1468-1485 (2015).

Sun, F., D. Littlejohn and M.D. Gibson: Ultrasonication extraction and solid phase extraction clean-up for determination of US EPA 16 priority pollutant polycyclic aromatic hydrocarbons in soils by reversed-phase liquid chromatography with ultraviolet absorption detection. Anal. Chim. Acta, 364, 1-11 (1998).

Tejeda-Agredano, M.C., S. Gallego, J. Vila, M. Grifoll, J.J. Ortega-Calvo and M. Cantos: Influence of the sunflower rhizosphere on the biodegradation of PAHs in soil. Soil Biol. Biochem., 57, 830-840 (2013).

Toal, M.E., C. Yeomans, K. Killham and A.A. Meharg: A review of rhizosphere carbon flow modelling. Plant Soil, 222, 263-281 (2000).

Vejan, P., R. Abdullah, T. Khadiran, S. Ismail and A.N. Boyce: Role of plant growth promoting rhizobacteria in agricultural sustainabilitya Review. Molecules, 21, 573 (2016). http:// dx.doi.org/ 10.3390/ molecules 21050573.
Willscher, S., L. Jablonski, Z. Fona, R. Rahmi and J. Wittig : Phytoremediation experiments with Helianthus tuberosus under different $\mathrm{pH}$ and heavy metal soil concentrations. Hydrometallurgy, 168, 153-158 (2017).

Yim, B., H. Kim, J. Kim, H. Kim, E.J. Won and Y.M. Lee: Identification and molecular characterization of cytochrome P450 (CYP450) family genes in the marine ciliate Euplotes crassus : the effect of benzo[a]pyrene and beta-naphthoflavone. Comp. Biochem. Phys. C, 196, 71-80 (2017).

Zaidi, A., E. Ahmad, M.S. Khan, S. Saif and A. Rizvi: Role of plant growth promoting rhizobacteria in sustainable production of vegetables: Current perspective. Sci. Hortic., 193, 231-2319 (2015.

Zhao, Y., B. Hong, Y. Fan, M. Wen and X. Han: Accurate analysis of polycyclic aromatic hydrocarbons (PAHs) and alkylated PAHs homologs in crude oil for improving the gas chromatography/mass spectrometry performance. Ecotoxicol. Environ. Saf., 100, 242250 (2014). 